\title{
Comparative Wound Healing Study of Ocimum tenuiflorum Leaves Extract and its Formulation on Sprague Dawley Rats
}

\author{
Rohini Jayaraman ${ }^{1}$, Nasir Yusoff ${ }^{2}$ and Rabeta Mohd Salleh ${ }^{1 *}$ \\ ${ }^{1}$ Food Technology Division, School of Industrial Technology, Universiti Sains Malaysia, 11800 Gelugor, Penang, \\ Malaysia \\ ${ }^{2}$ Department of Neurosciences, School of Medical Sciences, Health Campus, Universiti Sains Malaysia, 16150 Kubang
}

Kerian Kelantan, Malaysia

\begin{abstract}
This study has been designed to compare the leaves extract of Ocimum tenuiflorum with soy lecithin and the leaves extract of Ocimum tenuiflorum only and find out its effectiveness on wound healing properties. Drug release study was also evaluated to obtain a brief idea on the release of the drug after consumption of the formulation and extract. The wound healing effectiveness study suggest that the formulated extract has better wound healing activity in comparison to extract which is more similar to the standard drug which was used as positive control. It was also found that the drug release activity of the formulation shows sustained release of the marker compound in when compared to the extract. Thus, it can be concluded that the improved wound healing activity of the formulation could be due to the sustained released of the compounds which present that act accordingly to improve the activity. Further study on its mechanism of action need to done to understand it activity better.
\end{abstract}

Keywords: wound healing; Ocimum tenuiflorum; in vivo; soy lecithin

\section{INTRODUCTION}

Wound healing is a natural process that restore damaged wound tissue into its original state when injury occurred (Tan et al., 2019). Prolonged inflammation condition can eventually affect the wound healing process (Maver et al., 2018). This healing process need the association of several body physiological activities such as reversal of cytotoxicity, suppression of inflammation and stimulation of cellular viability and proliferation (Amin et al., 2015). Hence, the aim of wound care is to ensure the products to promote tissue healing in shortest time possible, avoid secondary infections and reduce pain, discomfort and scarring by inducing tissue repair and regeneration (Builders et al., 2013).

Herbal medicines have been used worldwide for several decades. The reason behind it was due to the presence of the active phytoconstituents (Jahan et al., 2016). Thus, these plants can be used as an alternative and complementary herapeutics for improvement in wound healing process based on their multiple active and effective compounds (Hajialyani et al., 2018). According to Mazumder et al. (2016), formulating plant extracts improve its effectiveness by resolving its physicochemical property issues; hence better biological and therapeutics activities can be seen.

Ocimum tenuiflorum is widely known for its medicinal properties. In Ayurvedic herb, it is called Tulsi, listed in Malaysian Herbal Monograph and Globinmed has proven lots of medicinal benefits including wound healing (Malaysian Herbal Monograph 2015, 2019). In this study, $O$. tenuiflorum leaves extract has been formulated using soy lecithin complex formulation.

Lecithin can be generally found in animal tissues and vegetables and its extensive amount can be obtained especially from soy bean (Pires et al., 2017). Scientifically, lecithin is referring to phosphatidylcholine which was

*Corresponding author's e-mail: rabeta75@gmail.com 
historically known as lipid molecules containing phosphate group that is isolated from brain or egg (Gnananath et al., 2017). Amphiphilic properties of lecithin have shown increased in solubility and ease the permeation across the phospholipid bilayer of epithelium (Zhou et al., 2017) which is beneficial because it enhances the bioavailability simultaneously (Lu et al., 2018).

Similar to other flavonoids type compounds, apigenin also have been proposed to have antioxidant, anti-inflammatory, antimicrobial, anticancer and other medicinal properties (Erdogan et al., 2017). It was reported that apigenin helps the epithelization of the wound and possess anti-inflammatory properties which is an essential factor in wound healing process (Manivannan, 2016). In this paper, apigenin was used as a marker compound to study the drug release activity. Apigenin was selected based on the liquid chromatographymass spectrometry (LCMS) screening of the leaves extract. Many topical based product is available, hence this study has been designed to compare the leaves extract of Ocimum tenuiflorum with soy lecithin and the leaves extract of Ocimum tenuiflorum only and find out its effectiveness on wound healing properties especially to patients who do not like the peculiar taste/odour of snakehead fish and sea cucumber when taken orally.

\section{MATERIALS AND METHOD}

\section{A. Plant Material Collection and Extraction}

O. tenuiflorum plants were collected from the botanical garden, Perak only to resolve the issue about standardization of apigenin as marker compound. The plant was identified and authenticated from School of Biological Sciences, Universiti Sains Malaysia (USM) (Herbarium number is 11400)

A $1 \mathrm{~kg}$ of the leaves was washed with running tap water. The washed leaves were oven dried at $60^{\circ} \mathrm{C}$ for 24 hours. Then the weight of the dried sample was approximately $100 \mathrm{~g}$, and the leaves were ground to fine powder mesh 6o. The weight of the powdered leaves was approximately $90 \mathrm{~g}$ and stored in air-tight container in freezer $-20{ }^{\circ} \mathrm{C}$.

Aqueous extraction method was chosen based on the effectiveness of the plant in wound healing study done by Shetty et al. (2008) while the extraction steps according to
(Rabeta \& Lai, 2013) with some modification. Approximately $10 \mathrm{~g}$ (modification step) of leaves was mixed with $100 \mathrm{ml}$ of distilled water in a conical flask. The mixture was then shaken in an orbital shaker at $160 \mathrm{rpm}$ at $27^{\circ} \mathrm{C}$ for 24 hours followed by centrifugation at $3500 \mathrm{rpm}$ (modification step) for 30 minutes to separate the sediment and supernatant. The supernatant was transferred to a beaker and evaporated using the oven at $60{ }^{\circ} \mathrm{C}$ until thin layer dry extract was obtained. The obtained extract was stored in an airtight container in freezer $-20{ }^{\circ} \mathrm{C}$ until use.

\section{B. Formulation Preparation}

The formulation was prepared according to Wang et al. (2013). Soy lecithin and extract were dissolved separately using 50\% ethanol until complete dissolution and mix together. The solutions beaker was closed and allowed to mix until equilibrium was reached for about 3 hours with agitation at $90 \mathrm{rpm}$ in orbital shaker. During solvent evaporation, the beakers were opened and placed in oven at $45{ }^{\circ} \mathrm{C}$ until dried solids were obtained.

\section{In vivo Wound Healing Study}

Comparative wound healing study was conducted according Shetty et al. (2008) with slight modifications. Modification done was the dissolving agent used for diluting extract and number groups tested. Comparative wound healing study was conducted according Shetty et al. (2008) with slight modifications. Modification done was the dissolving agent used for diluting extract and number groups tested.

Total of sixteen male rats were used in this study. Adult female Sprague-dawley (SD) rats age 8-10 weeks old, weighing around $180-200 \mathrm{~g}$ were used in this experiment. Rats were acclimatized under $12 \mathrm{~h}$ light and dark cycle and allowed for free access to food and water. The experiment was carried out in accordance to Universiti Sains Malaysia (USM) animal ethics committee guidelines and approval. The ethical approval number was USM/IACUC/2018/ (111) (915).

All the rats were individually caged and divided in four groups which are the negative control, positive control, formulation and extract. Negative control group received 200 $\mathrm{mg} / \mathrm{kg} \mathrm{BW}$ of plant lecithin solution, positive control group received $222 \mathrm{mg} / \mathrm{kg}$ BW of Channa striatus solution while $400 \mathrm{mg} / \mathrm{kg} \mathrm{BW}$ and $200 \mathrm{mg} / \mathrm{kg} \mathrm{BW}$ of formulation and leaves 
extract were given to formulation and extract group, respectively. Religious and vegetarian lifestyle choices may prohibit certain consumer groups from taking animal-based wound healing products (Boyer, 2013). Effective wound care from plant-based is needed because some people do not like the peculiar taste of Channa striatus and sea cucumber when taken orally, which are the popular animal-based products with wound healing properties. In our in vitro study showed that, at dosage of $400 \mathrm{mg} / \mathrm{kg}$ body weight the wound heals faster than the extract treated group (Rohini et al., 2019). The dose treatment for extract group was obtained from (Shetty et al., 2008) as baseline dose and equivalent dose of formulation was chosen for the formulation group treatment. All the treatments were done once daily via $50 \mu$ oral administration using oral gavage needle for 15 days until the treatment group animals wound closed. Positive control dose was calculated by converting human dose to rat dose based on animal equivalent dose table (Nair \& Jacob, 2016).

\section{Wound Creation}

Rats were anaesthetized using ketamine and xylazine intraperitoneally $50 \mathrm{mg} / \mathrm{kg}$ and $5 \mathrm{mg} / \mathrm{kg}$ body weight (BW) respectively prior to wounding. Excision wound was created by cut off a circular piece of skin, thickness $\sim 500 \mathrm{~mm} 2$ at the dorsal interscapular region of the rat. The wound size was traced using a plastic sheet on the day of wounding and consequently every three days until healing was complete. The wound contraction was calculated using the formula below (Shetty et al., 2008):

Wound contraction $=($ healed wound area/ total wound area) $\times 100$

\section{E. In vitro Drug Release Assay}

Equivalent amount of extract and formulation samples were weighed and dissolved in $4 \mathrm{ml}$ of water. The samples were sonicated at $45^{\circ} \mathrm{C}$ at $60 \mathrm{kHz}$ for $15 \mathrm{~min}$ until the samples were completely dissolved. The samples were transferred to 4-inch long dialysis tube (cellulose membrane molecular weight cut off range 12,000-14,000) separately and secured with clips at both ends. The tube was incubated in a beaker containing $80 \mathrm{ml}$ of PBS, $\mathrm{pH} 7.4$ in beaker at $37^{\circ} \mathrm{C}$ under mild shaking in incubator shaker. About $1 \mathrm{ml}$ of aliquot was withdrawn from the incubation medium of both samples at specific intervals of o, 15, $30 \mathrm{~min}$ and every $1 \mathrm{~h}$ for $12 \mathrm{~h}$. Each time an aliquot was withdrawn, equal volume of PBS was added to the solution. The amount of drug release into the incubation medium was analyzed using UV- spectrophotometer at wavelength of $340 \mathrm{~nm}$ using apigenin (API) as reference (Telange et al., 2017).

\section{G. Statistical Analysis}

Results were tabulated with SPSS software version 20 and displayed as mean +SEM. The SEM quantifies how precisely you know the true mean of the samples. Data were statistically analyzed using one-way ANOVA and Tukey post host descriptive test where $\mathrm{p}<0.05$ were considered statistically significant.

\section{RESULT AND DISCUSSION}

\section{A. In vivo Wound Healing Study}

The comparison was made based on the treatment. Figure 1 shows the wound healing activity of four different groups. On 9th day, it was observed a significant reduction $(\mathrm{p}<0.05)$ in wound size for the formulation group compared to the extract group. Besides, it was also observed that the wound healing activity of the formulation treated group was equivalent to the positive control group. In overall, it can be observed that the formulation treated wound closes faster $(\mathrm{p}<0.05)$ when compared to extract treated group which is within fifteen days of the study. In Figure 2, the macroscopic view of the rat wounds before and after treatment of the test samples support that the wound is completely closed within the study period for formulation treated rats when compared to the extract treated rats. 


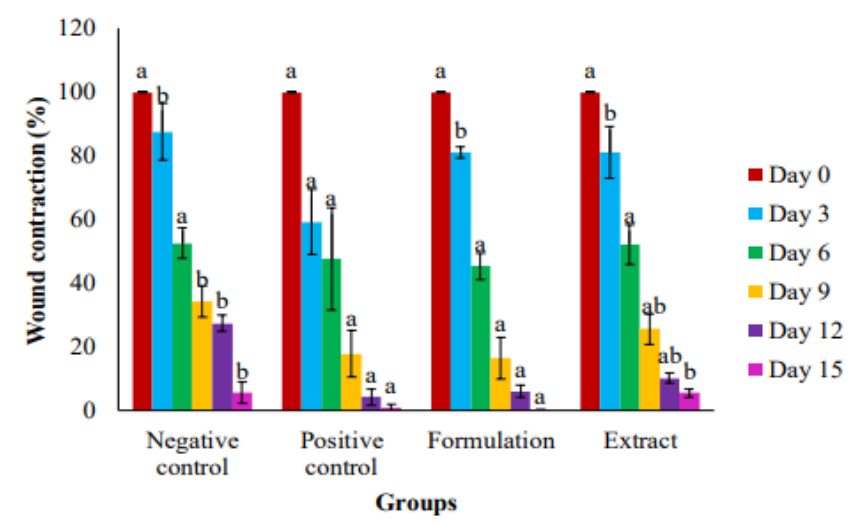

Figure 1. The wound healing activity of different treatment given to rats

*Value represented as mean \pm SEM $(n=4)$ and different alphabets were considered statistically significant when $(\mathrm{p}<0.05)$.

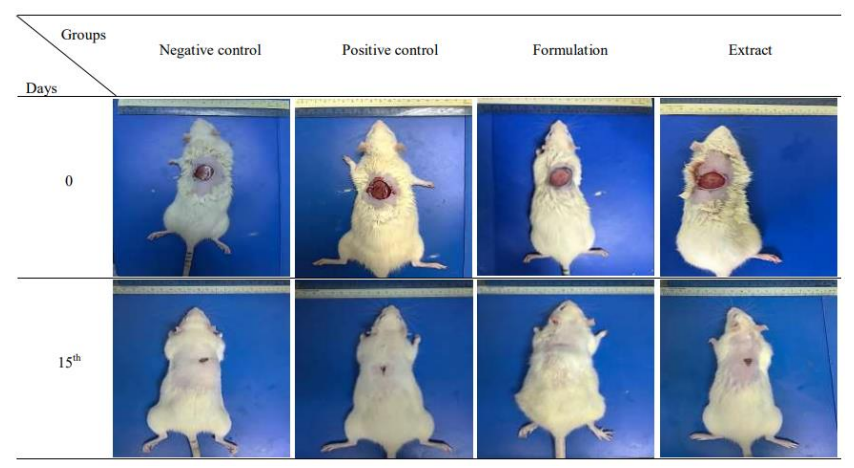

Figure 2. Macroscopic view of wound healing process in rats treated with formulated and non-formulated aqueous extract of Ocimum tenuiflorum leaves

It was also of interest to determine whether extract formulated, could enhance the wound healing activity. Based on the obtained results, it showed that the formulation treated rats wound healed faster compared to the extract treated rats. This suggest that the formulation do enhance the wound healing activity of the extract when it is formulated rather than its original state. This improvement in the wound healing activity could be related with the complex action formed between the lecithin.

Religious and vegetarian lifestyle choices may prohibit certain consumer groups from taking animal-based wound healing products (Boyer, 2013). Effective wound care from plant-based is needed because some people do not like the peculiar taste of snakehead fish and sea cucumber when taken orally, which are the popular animal-based products with wound healing properties. People with seafood allergies should avoid the use of sea cucumber for wound healing purpose (Wan Zanariah et al., 2016). Plant-based wound healing may cause minimal adverse effects (Ekor, 2013).

\section{B. In vitro Drug Release Assay}

Figure 3 shows that the amount of API released to the environment (PBS solution) was significantly increased ( $p<0.05$ ) up to 7 th hours of study in both extract and formulation. However, the API release in extract had slight fluctuation during the 8th hour and increases slightly up to 10th hour. In contrast, the API release in formulation was significantly increased ( $\mathrm{p}<0.05$ ) up to 12th h of study when compared to extract whereby the release reduces significantly $(\mathrm{p}<0.05)$ after 10th h.

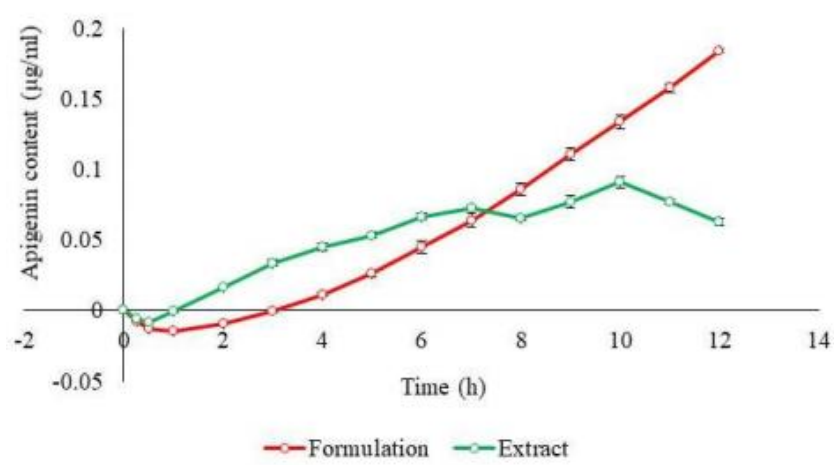

Figure 3. In vitro drug release of extract and formulation

In drug release study, the release of target marker compound API was observed to be increased up to $12 \mathrm{~h}$ when compared to extract which has fluctuated release. This result indicates that the complex action with lecithin has control the drug release whereby a sustained release of the drug can be observed. The sustained release activity may be due to the gradual drug dissociation from the complex and later diffuse to the medium through the membrane (Freag et al., 2018). Hence, it can be said that the wound healing activity of the formulation was better and improved in formulation treated group was because of the slow release of the compounds. The release of compounds was controlled by the complex formed with lecithin which help the compounds stay longer in the body to give a better effect rather administering extract which shows fluctuated release after few hours.

Besides that, it was believed that by formulating the extract with lecithin, which is the type of phospholipid having both hydrophilic and hydrophobic site increases the bioavailability by wetting and dispersion action when the solubility was 
enhance (Semalty et al., 2010). Therefore, this can be said that the phospholipid complex of extract may have improve the absorption of active compounds to the lipid barriers in gastrointestinal tract after oral administration (Semalty et al., 2012). This could be another reason why improvement in wound healing activity was observed in formulation treated group compared to extract treated group. Similarly, literature studies also reported that drugs or compounds that have been formulated with phospholipid have improved its effectiveness by improving its absorption to target site when compared to the application of crude compounds or drugs alone (Kumar et al., 2014).

\section{CONCLUSION}

The comparative study between the extract and formulation suggest that, formulating the extract with phospholipid has improved its wound healing effectiveness by sustained release of the compounds to the target site which can be seen through the drug release study. Hence, formulating the extract to improved it biological activity has been a good attempt on Ocimum tenuiflorum leaves. Further study on its mechanism of action need to done to understand it activity better.

\section{ACKNOWLEDGEMENT}

This work funded by a grant of Universiti Sains Malaysia RU grants (1001/PTEKIND/ 812176) contributed to the funding of this research.

\section{REFERENCES}

Amin, ZM, Koh, SP, Yeap, SK, Abdul Hamid, NS, Tan, CP \& Long, K 2015, 'Efficacy study of broken rice maltodextrin in in vitro wound healing assay', BioMed Research International, 2015, pp. 1-12.

Baie, SH \& Sheikh, KA 2000, 'The wound healing properties of Channastriatus-cetrimide cream-- tensile strength measurement', J Ethnopharmacol, vol. 71, no. 1-2, pp. 93100.

Boyer, D 2013, 'Cultural considerations in advanced wound care', Advances in Skin \&Wound Care, vol. 26, pp. 110-111.

Builders, PF, Kabele-Toge, B, Builders, M, Chindo, BA, Anwunobi, PA \& Isimi, YC 2013, 'Wound healing potential of formulated extract from hibiscus sabdariffa calyx', Indian Journal of Pharmaceutical Sciences, vol. 75, pp. 45-52.

Dorsett-Martin, WA 2004, 'Rat models of skin wound healing: a review', WoundRep, vol. 12, pp. 591-599.

Ekor M 2013, The growing use of herbal medicines: issues relating to adverse reactions and challenges in monitoring safety.

Frontiers in Pharmacology, vol. 4 pp. 177.

Erdogan, S, Turkekul, K, Serttas, R \& Erdogan, Z 2017, 'The natural flavonoidapigenin sensitizes human $\mathrm{CD}_{44}+$ prostate cancer stem cells to cisplati therapy', Biomed Pharmacother, vol. 88, pp. 210-217.

Freag, MS, Saleh, WM \& Abdallah, OY 2018, 'Self-assembled phospholipid-based phytosomal nanocarriers as promising platforms for improving oral bioavailability of the anticancer celastrol', International Journal of Pharmaceutics, vol. 535, pp. 18-26.

Gnananath, K, Nataraj, KS \& Rao, BG 2017, 'Phospholipid complex technique for superior bioavailability of phytoconstituents', Advanced Pharmaceutical Bulletin, vol. Apr, no. 71, pp. 35-42.

Hajialyani, M, Tewari, D, Sobarzo-Sánchez, E, Nabavi, SM, Farzaei, MH \& Abdollahi, M 2018, 'Natural product-based nanomedicines for wound healingpurposes: therapeutic targets and drug delivery systems', International Journal of Nanomedicine, vol. 13, pp. 5023-5043.

Jahan, N, Aslam, S, Rahman, Kur, Fazal, T, Anwar, F \& Saher, R 2016, 'Formulation and characterisation of nanosuspension of herbal extracts for enhanced antiradical potential', Journal of Experimental Nanoscience, vol. 11, pp. $72-80$.

Kumar, M, Ahuja, M \& Sharma, S 2008, 'Hepatoprotective study of curcumin-soya lecithin complex', Scientia Pharmaceutica, vol. 76, pp. 761-774.

Lu, M, Qiu, Q, Luo, X, Liu, X, Sun, J, Wang, C, Lin, X, Deng, $\mathrm{Y}$ \& Song, Y 2018, 'Phyto-phospholipid complexes (phytosomes): a novel strategy to improve the bioavailability of active constituents', Asian Journal of Pharmaceutical Sciences, vol. 14, no. 3, pp. 265-274. 
Ma, H, Chen, H, Sun, L, Tong, L \& Zhang, T 2014, 'Improving permeability andoral absorption of mangiferin by phospholipid complexation', Fitoterapia, vol. 93, pp. 54-61.

Malaysian Herbal Monograph 2015 2019, Institute for Medical Research (IMR), Ministry of Health, Malaysia.

Manivannan, R 2016, 'Isolation of apigenin-7-O-(6"-O-Ecaffeoyl)- $\beta$-D-glucopyranoside from Leucas aspera L. with anti-inflammatory and wound healing activities', Journal of Pharmacy \& Pharmacognosy Research, vol. 4, no. 2, pp. 5461.

Maver, T, Kurečič, M, Smrke, DM, Kleinschek, KS \& Maver, U 2018, 'Plant derived medicines with potential use in wound treatment', Herbal Medicine: IntechOpen, pp. 121150.

Mazumder, A, Dwivedi, A, Du Preez, JL \& Du Plessis, J 2016, 'In vitro wound healing and cytotoxic effects of sinigrinphytosome complex', International Journal of Pharmaceutics, vol. 498, pp. 283-293.

Nair, AB \& Jacob, S 2016, 'A simple practice guide for dose conversion between animals and human', Journal of Basic and Clinical Pharmacy, vol. 7, no. 2, pp. 27-31.

Pires, LN, Brandão, GC \& Teixeira, LS 2017, 'Determination of phospholipidsin soybean lecithin samples via the phosphorus monoxide molecule by high-resolution continuum source graphite furnace molecular absorption spectrometry', Food Chemistry, vol. 225, pp. 162-166.

Rabeta, MS \& Lai, SY 2013, 'Effects of drying, fermented and unfermented tea of Ocimumtenuiflorum Linn. on the antioxidant capacity', International Food Research Journal, vol. 20, pp. 1601-1608.

Rohini, J, Mansoureh, NV, Fouad Saleih, RAl-S, Rabeta, MS \& Amin Malik Shah, AM 2019, 'Preliminary screening on wound healing potential of Ocimumtenuiflorum using in vitro assays', Food Research, vol. 3, no. 3, pp. 258-264.

Semalty, A, Semalty, M, Singh, D \& Rawat, M 2010, 'Preparation and characterization of phospholipid complexes of naringenin for effective drug delivery', Journal of Inclusion Phenomena and Macrocyclic Chemistry, vol. 67, pp. 253-260.

Semalty, A, Semalty, M, Singh, D \& Rawat, M 2012, 'Phytophospholipid complex of catechin in value added herbal drug delivery', Journal of Inclusion Phenomena and Macrocyclic Chemistry, vol. 73, pp. 77-386.

Shetty, S, Udupa, S \& Udupa, L 2008, 'Evaluation of antioxidant and wound healing effects of alcoholic and aqueous extract of Ocimum sanctum Linn in rats',
Evidence-Based Complementary and Alternative Medicine, vol. 5, pp. 95-101.

Tan, WS, Arulselvan, P, Ng, S-F, Che Norma, MT, MurniNazira, S \& Sharida, F 2019, 'Improvement of diabetic wound healing by topical application of Vicenin-2 hydrocolloid film on Sprague Dawley rats', BMC Complementary and Alternative Medicine, vol. 19, no. 20, pp. 1-16.

Telange, DR, Patil, AT, Pethe, AM, Fegade, H, Anand, S \& Dave, VS 2017, 'Formulation and characterization of an apigenin-phospholipid phytosome (APLC) for improved solubility, in vivo bioavailability, and antioxidant potential', European Journal of Pharmaceutical Sciences, vol. 108, pp. 36-49.

Wan Zanariah WAM, Sundara RM, Kamaruddin A, Sarah IB \& Long CM 2016, 'Safety and efficacy of sea cucumber containing products', Archives of Pharmacy Practice, vol. 7 no. 5, pp. 48-52.

Wang, D, Li, H, Gu, J, Guo, T, Yang, S, Guo, Z, Zhang, X, Zhu, W \& Zhang, J 2013, 'Ternary system of dihydroartemisinin with hydroxypropyl- $\beta$-cyclodextrin and lecithin: simultaneous enhancement of drug solubility and stability in aqueous solutions', Journal of Pharmaceutical and Biomedical Analysis, vol. 83, pp. 141-148.

Zhou, Y, Dong, W, Ye, J, Hao, H, Zhou, J, Wang, R \& Liu, Y 2017, 'A novel matrix dispersion based on phospholipid complex for improving oral bioavailability of baicalein: preparation, in vitro and in vivo evaluations', DrugDelivery, vol. 24, pp. 720-728. 